\title{
Issues in adolescent asthma: what are the needs?
}

\author{
John F Price
}

Although asthma is increasing in teenagers it is often not recognised. This may be partly due to a lack of perception of the disease and partly to a reluctance to seek medical advice. A greater awareness of asthma in schools and health checks for teenagers in general practice may help to improve diagnosis. In addition, strategies to discourage cigarette smoking should be targeted at young people with asthma. Asthma education is important, but in itself will not resolve the non-compliance with treatment that

\section{Asthma education is important, but in itself will not resolve the non- compliance with treatment that is common in adolescents.}

is common in adolescents. Treatment plans need to be negotiated, not dictated, and are more likely to succeed with parental and peer group support. One barrier to compliance is a general antagonism to regular daily medication. Teenagers are more likely to comply with once or twice daily regimens than with treatment three or four times daily. Inhaled bronchodilator therapy is preferred to oral therapy, although oral anti-inflammatory compounds may have advantages in compliance.

\section{Recognition of asthma}

Department of Child Health, King's College School of Medicine and Dentistry, London, UK J F Price a disagreeable period of turmoil, awkwardness, rebelliousness, and unpredictability, to be tolerated then quickly forgotten. The other familiar aphorism detrimental to the care of adolescents is that "children grow out of their asthma". Asthma is almost as common in adolescence as it is in young children and more common than it is in adults. In New Zealand $32-38 \%$ of $12-15$ year olds had experienced wheezing illness during the year preceding the study. ${ }^{1}$ Diagnosed asthma occurred in $16.5 \%$ of Australian children of the same age. ${ }^{2}$ In the Netherlands the figure was $19 \%$ for a group aged 10-23 years. ${ }^{3}$ There are approximately 4.2 million teenagers in the UK $(8.4 \%$ of the total population). If the prevalence of asthma in this group is the same as it is in The Netherlands, then more than 800000 of them have asthma. In Scandinavia the prevalence of asthma in adolescents is low. However, in Finland it increased from $1 \%$ in 1977 to $2 \cdot 8 \%$ in 1991 (table 1). ${ }^{4}$

Fortunately, asthma deaths are uncommon in adolescents, but in the UK between 1990 and 1992 three times as many children aged 10-14 years and six times as many aged 15-20 years have died of asthma as those aged between 5 and 10 years. Furthermore, asthma deaths were more frequent in boys than girls, but the gap narrowed in the late teens (table 2 ). ${ }^{5}$

The discrepancy between the data in table 1 - which indicates a prevalence of wheezing illness of over $30 \%$ in New Zealand obtained using video techniques and a standardised written questionnaire ${ }^{1}$ - and that of $16.5 \%$ for diagnosed asthma in Australia ${ }^{2}$ suggests that asthma may be underdiagnosed in young people. Further evidence comes from the study of the prevalence of asthma in young people in The Netherlands. Screening by questionnaire and spirometry identified $19 \%$ of the population studied as having asthma, but asthma had been recognised by the general practitioner in less than half of them. Male sex, a past history of "bronchitis", and a family history of atopy increased the likelihood of recognition of asthma. ${ }^{3}$ Possible reasons for the failure to diagnose asthma are that young people may have poor perception of asthma symptoms or that they may be reluctant to consult their doctor about them.

It is well known that some patients with asthma are unaware of airways obstruction or underestimate the degree of its severity. Although no studies specific to teenagers have been carried out, Rubinfeld and Pain investigated the perception of wheezing by adults in whom asthma was induced by bronchial challenge. Some were found to be quite un-
Table 2 Mortality due to asthma in the UK between 1990 and $1992^{5}$

\begin{tabular}{lcccc}
\hline \multicolumn{5}{c}{ Age (years) } \\
\cline { 2 - 5 } & $0-4$ & $5-9$ & $10-14$ & $15-19$ \\
\hline Population (millions) & $3 \cdot 54$ & $3 \cdot 26$ & $3 \cdot 13$ & $3 \cdot 11$ \\
Boys & 22 & 9 & 31 & 50 \\
Girls & 12 & 5 & 12 & 37 \\
Total & 34 & 14 & 43 & 87 \\
\hline
\end{tabular}


aware of any symptoms when their forced expiratory volume in one second $\left(\mathrm{FEV}_{1}\right)$ was less than $50 \%$ of predicted values. Others felt mildly wheezy with an $\mathrm{FEV}_{1}$ of less than $30 \%$ of predicted. ${ }^{6}$

Four years ago Market and Opinion Research International (MORI) carried out a qualitative survey of adolescents with asthma on behalf of the UK National Asthma Campaign. ${ }^{7}$ Forty six young people with asthma aged 13-16 years were recruited from schools throughout the UK. Groups of between six and nine individuals took part in topic guided discussions. It emerged that only two of the 46 attended an asthma clinic, only 25 had undergone peak flow measurement at some time, and most had poor knowledge of their asthma and limited understanding of its management. Furthermore, many relied heavily on pharmacists to explain their medication. The survey revealed a reluctance by these teenagers to visit their general practitioner or attend outpatient clinics.

One place where undertreated or undiagnosed asthma might be recognised is at school. About half of all school age children with asthma are unable to complete games periods because of asthma. ${ }^{8}$ Unfortunately, many teachers in the UK have little knowledge of the relationship between asthma and exercise. In one survey over half of the teachers questioned considered that asthmatic children were less competent at sporting activities but few were aware that this was because the physical activity provoked wheezing or that it could be prevented by pretreatment with a $\beta$ agonist bronchodilator. 9 Teachers need more structured information if their observations during play or games periods are to help identify undiagnosed asthma in teenagers. A survey of adolescent athletes suggested that screening followed by formal exercise testing might be one way of identifying asthma. Previously unrecognised exercise-induced asthma was found in $29 \%$ of adolescent athletes identified by medical history and spirometry to be at risk. ${ }^{10}$ Formal exercise testing has the disadvantage that it is very time consuming if applied to large numbers of children. Also, it may not reveal asthma that has been asymptomatic for several months. ${ }^{11}$

An alternative approach is to invite adolescents to general practices for health checks. This offers the opportunity both for recognising asthma and for giving advice about other health issues such as diet, physical activity, contraception, alcohol consumption, and cigarette smoking.

The willingness of young people to attend health checks was tested recently in three UK general practices - one in an inner city area, another in a country town, and a third in a rural area. The aim of this particular study was to address the issue of cigarette smoking but the invitation made no special mention of smoking. Up to three invitations were sent out to each individual. Perhaps surprisingly, the response of 13,15 , and 17 year olds was very positive and $73 \%$ of those invited attended for checkups. ${ }^{12}$
This and another study of screening of adolescents in general practice, which achieved a $50 \%$ attendance on a single invitation, ${ }^{13}$ suggest that, if approached personally, teenagers are willing to listen to advice about their health. An unexpected bonus, expressed by the practice staff who conducted the first study, was the opportunity to begin a good adult-type relationship with the teenagers based on the concept of a healthy lifestyle. ${ }^{12}$

\section{Self-image and risk taking}

The adolescent environment is wider and often more hostile than that of the younger child. To be able to cope with the new environment adolescents must develop certain attributes such as personal autonomy and reduced dependency on parents and family, which is natural in early childhood, and increased intimacy with peers based on a combination of preadolescent experiences and newly acquired autonomy. At the same time adolescents are driven by and must respond to new and powerful sexual impulses. The fierce desire to achieve independence from pre-adolescent family ties is matched by an intense aversion to being different from the peer group. An almost inevitable consequence of this is risk taking behaviour which tests new boundaries in relationships with family and peers.

\section{Asthma may make it more difficult for adolescents to arrive successfully at competent adulthood...}

Asthma may make it more difficult for adolescents to arrive successfully at competent adulthood for several reasons including: (1) continued dependency on parents because adolescents and their parents attend outpatient or asthma clinics together and parents share the management of the adolescent's disease; (2) coughing or wheezing during physical activity such as sport and dancing; and (3) the need to use highly visible treatment which makes young people with asthma different from their friends and may lead to isolation. In addition, the desire not to be seen taking treatment may contribute to non-compliance with the treatment.

Investigation of self-image, self-esteem, and cognitive and emotional disturbance in asthmatic adolescents has produced differing results. One study using the Offer Self-Image Questionnaire failed to demonstrate any differences between asthmatic adolescents seen in a private outpatient allergy practice and nonasthmatic controls. In fact, the self-image of the asthmatic girls was better in some respects than that of their non-asthmatic counterparts. ${ }^{14}$ On the other hand, a study of 12-18 year olds with chronic diseases including asthma, using a questionnaire compiled from the Beck Depression Inventory and the Rosenberg Scale of Self-Esteem, found they had higher depression 
scores and lower self-esteem than healthy age matched controls. ${ }^{15}$ All of the children in the second study had been admitted to hospital at least twice during the previous year and so may have represented a group with more severe disease than in the first study. This impression is borne out by the results of a third study which showed that teenagers with mild asthma did not have any greater cognitive or emotional disturbance than those without asthma. However, irrational beliefs, anxiety, depression, and hostility were strongly associated with severe asthma. ${ }^{16}$

Cigarette smoking is a common risk taking activity in teenagers. Most adult smokers take up smoking as teenagers and the earlier children start smoking the less likely they are to give it up. ${ }^{17}$ A survey conducted in the UK in 1990 concluded that $27 \%$ of girls and $26 \%$ of boys in the fifth year of secondary school (aged 15-16 years) were smoking regularly (at least one cigarette per week). ${ }^{18}$ Cigarette smoking is almost as common among adult asthmatics as it is in non-asthmatic subjects. Adolescents with asthma past or present may represent a group particularly likely to take up smoking. A questionnaire used to discover perceptions and beliefs about smoking in 13-16 year olds revealed that those with a past history of asthma had a more positive attitude towards cigarettes, a self-image more closely linked with their perception of smokers, and a stronger intention to become smokers themselves than non-asthmatics. ${ }^{19}$

The penalties for taking up smoking at a young age, such as increased risk of lung cancer, ${ }^{20}$ reduced asthma control and, for girls who smoke during pregnancy, a major risk of abnormal lung function in their infants, ${ }^{21}$ are irrefutable. A general awareness of these dangers does not seem to be sufficient to discourage teenagers from smoking. Other strategies are needed and it is encouraging that many teenagers seem to welcome an initiative from their general practitioners. Counselling in early adolescence by family doctors and practice nurses could potentially reduce the uptake of cigarette smoking by young asthmatic patients. The initial response of adolescents who attended health checks in the general practice study described earlier was that $60 \%$ of the smokers made an agreement with the practice doctor or nurse to give up smoking. ${ }^{12}$

The diagnosis of asthma ... is likely to provoke intense emotions and beliefs in adolescents.

\section{Education and compliance}

An approach that assumes that the teenager will follow the clinician's directions if asthma is explained and treatment recommendations demonstrated is often unsuccessful. ${ }^{22}$ Intelligence, education, and the ability to understand information about the nature of asthma bears little relationship to compliance. Even when clear written advice is given, as many as $75 \%$ of asthmatics do not take their medication correctly. ${ }^{23}$

The diagnosis of asthma, whether symptoms have just developed or the asthma is longstanding but previously unrecognised, is likely to provoke intense emotions and beliefs in adolescents. It may be very difficult to express these concerns either to parents or to doctors and reactions may take the form of anger, selfblame, fear, reduced sense of self-esteem, or denial. Most teenagers prefer to view asthma as episodic and find it hard to accept the need to take regular medication. A vital first step in management is to discover the teenager's anxieties about asthma and its treatment. Questions inviting a yes or no answer do not achieve this and open ended questions such as "What worries you about having asthma?" or permissive questions such as "Lots of teenagers tell me that they are unhappy about taking treatment every day. What sort of things worry you about taking treatment regularly?" are likely to be much more revealing. ${ }^{24}$ This sort of discussion helps to establish a two-way flow of information that moves towards the negotiation of a contract of management between the physician and the teenager. Negotiation is important because it will give the teenager some authority and less of a feeling that asthma and its treatment will impede progress towards adulthood. Where possible the clinician should enlist the involvement and support of parents in such negotiations as effective parental involvement in the healthcare of teenagers will improve compliance with treatment regimens.

Asthma management is also more likely to succeed if it is combined with ... peer support.

Asthma management is also more likely to succeed if it is combined with that most powerful of influences - peer support. Support groups give the opportunity for teenagers with asthma to share the burden of their illness and to see how others cope with their parents and peers as well as with their asthma attacks. An example is the "Support for Asthma Youth" initiative sponsored by the Asthma and Allergy Foundation of America. Each group has a core of teenagers with asthma supported by a respiratory nurse or asthma educator and a physician who gives advice. This particular network produces written and telephone advice and organises group sessions to increase the understanding of asthma. The group sessions also offer the opportunity to share practical tips on asthma management. As adolescents employ some of the learning tools of childhood, including play, the most effective methods for education have proved to be role play and learning games. Information in the form of booklets and videos is a useful supplement to, but not a substitute for, personal contact. The same applies to treatment plans. A plan of asthma management once worked out with the 
Table 3 Partnership in asthma management

Recognise expectations and concerns

Negotiate contracts, enlist family support

Keep the treatment plan simple

Write down what to do if the asthma gets worse, improves, or there is an attack

Review and reward efforts

teenager and his parents should be written down. Simple treatment plans are the most effective. They need to contain three essential elements: what to do if the asthma gets worse, how to reduce treatment if the asthma improves, and how to manage an acute attack. This gives teenagers some responsibility for and control over their disease, but they also need to know when to seek medical help (table 3).

\section{Treatment}

Administration of asthma medication directly to the airways by inhaler confers the great advantage that small doses can be given, thus reducing the risk of side effects. The large volume $(750 \mathrm{ml})$ spacer device with a one-way valve is an efficient, easy to use delivery system. However, for teenagers, it is cumbersome and embarrassing. It cannot be carried unobtrusively and, in the teenager's bedroom, it is immediately obvious to friends. The unmodified metered dose inhaler (MDI) is much easier to conceal and tends to be more popular with teenagers. Unfortunately it is seldom used properly. More than two thirds of adults ${ }^{2526}$ and half of children ${ }^{27}$ with asthma do not use the correct method even after instruction.

A study of MDI use by junior paediatric medical staff in a New York teaching hospital highlights the problem. When asked to demonstrate inhalation via an MDI $48 \%$ did not shake the inhaler and $40 \%$ failed to exhale before use; $29 \%$ actuated the inhaler more than once during a single breath and $54 \%$ did not hold their breath after inhalation. ${ }^{28}$ This lack of knowledge and expertise among asthmatics and clinicians is striking, but it is probable that even those teenagers who know how to use the MDI correctly do not do so when they are with their peers. Although small and convenient to carry, the MDI becomes very obvious if the proper inhalation technique is used - first exhaling, then inhaling with the head tilted back, and finally holding the breath after inhalation. We have little specific information about the techniques used by teenagers to inhale medication via MDIs, but the least easily observed method is certainly not the most efficient.

Table 4 Preventive medication for asthma (France, Germany, Italy, USA, UK)

\begin{tabular}{llll}
\hline & \multicolumn{3}{l}{ Age (years) } \\
\cline { 2 - 4 } & $0-9$ & $10-19$ & $20+$ \\
\hline Population (\%) & 13 & 12 & 75 \\
Prescriptions (\%) & 46 & 22 & 78 \\
Cromoglycate & 10 & 12 & 78 \\
Inhaled corticosteroids & 36 & 15 & 49 \\
Ketotifen & 4 & 5 & 91 \\
Theophylline & & & \\
\hline
\end{tabular}

Source IMS AG (1994).
Two other factors likely to influence the willingness of teenagers to take medication are frequency of administration and concern about side effects. Four classes of compound are widely used for regular or preventive medication in children and adolescents with asthma: sodium cromoglycate, inhaled corticosteroids, ketotifen, and theophylline. There are wide variations in prescribing habits in different countries but when data from France, Germany, Italy, USA, and the UK were pooled, $22 \%$ of all prescriptions for cromoglycate, $12 \%$ for inhaled corticosteroids, $15 \%$ for ketotifen, and 5\% for theophylline were for 10-19 year olds who comprise about $12 \%$ of the total population (table 4). It is recommended that sodium cromoglycate be taken four times a day. There must be considerable doubt about compliance with a regimen with such a high frequency of administration. ${ }^{29}$ Compliance with a regimen of inhaled prophylactic medication in 9-16 year olds was found to be inversely related to the number of doses prescribed per day. The percentage of days when medication was taken as prescribed decreased from $71 \%$ for twice daily medication to $18 \%$ for four times daily medication. ${ }^{30}$

Inhaled corticosteroids are currently the most effective treatment for moderate and severe asthma in all ages and need be taken only twice daily. However, compliance with inhaled corticosteroid treatment may be influenced by anxiety about side effects. Such concerns about possible adverse effects, particularly effects on growth, are often expressed by the parents of young children with asthma; we do not know whether this is something that also worries teenagers. A physiological delay in the onset of puberty is often seen in asthmatic patients irrespective of the severity of disease or its treatment. It is conceivable that asthmatic teenagers who are smaller and less well developed than their peers might worry more about the possible adverse effects of treatment on their growth. However, what little evidence we have in adolescent asthma suggests that fears on growth suppression by inhaled corticosteroids during adolescence are unfounded. In a multicentre study in The Netherlands ${ }^{31}$ the growth of 40 asthmatic teenagers treated with budesonide $0.6 \mathrm{mg} /$ day for a median of 22 months was compared with the growth of asthmatic and non-asthmatic controls. Asthmatic boys grew more slowly than their agematched non-asthmatic peers irrespective of whether or not they were taking inhaled corticosteroids. This is compatible with their having a later onset of pubertal growth. However, the growth rate of asthmatic boys and girls treated with inhaled corticosteroids was no different from that of those who received only a $\beta$ agonist bronchodilator. ${ }^{31}$ Young people may also associate "steroids" with the androgenic variety used by some athletes. Although these anxieties about the side effects of inhaled corticosteroids are without foundation, they may still be a barrier to compliance.

Oral compounds that are taken only twice daily have potential advantages for treatment compliance in teenagers. This may help to 
Table 5 What are the needs?

Health checks, general practitioners, and schools Non-smoking strategy

Peer support groups

Agreed, simple, written treatment plan

Joint clinics for severe disease

explain the frequent prescription of ketotifen to asthmatic adolescents. Although useful in atopic pre-schoolchildren, clinical trials have not shown this compound to be highly effective in older children and adults. Its popularity may in part be attributed to ease of administration. Slow-release theophyllines have the same advantage of ease of administration, but the need for frequent dose adjustment during rapid pubertal growth ${ }^{32}$ makes their use impractical in many teenagers.

The leukotriene receptor antagonists, which are likely to become available on prescription for adults and adolescents in the near future, are also orally active. Our understanding of the role of the leukotrienes in childhood and adolescent asthma is still rudimentary. Levels of cysteinyl leukotrienes are raised during and one month after asthma attacks in young children, so one can speculate that upregulation of the arachidonic acid metabolic pathway may contribute to persistent inflammation of the airways in young asthmatics. ${ }^{33} \mathrm{We}$ must await the outcome of appropriate clinical trials before we know whether leukotriene receptor antagonists have a place in the treatment of young people with asthma. Certainly, an orally active prophylactic agent that can be taken twice a day is likely to appeal to teenagers, and may improve compliance.

\section{Concluding remarks}

In the UK most children with asthma do not attend hospital clinics and continuity of care is provided by their general practitioner. However, those with severe asthma, most of whom will not grow out of their symptoms, need hospital-based care as well. As they progress through adolescence teenagers become increasingly uncomfortable in paediatric wards and outpatient clinics. They need clinics where they can meet the chest physician who will take on their care before they transfer to a clinic for adults (table 5).

\section{Adolescent asthmatic patients are a distinct group of patients with different treatment requirements from either paediatric or adult patients.}

Adolescent asthmatic patients are a distinct group of patients with different treatment requirements from either paediatric or adult patients. It is important that physicians recognise adolescent needs and the importance of regular health checks, smoking, peer pressure, and the negotiation of treatment plans in this group of patients.

1 Robson B, Woodman K, Burgess C, Crane J, Pearce N, Shaw $\mathrm{R}$, et al. Prevalence of asthma symptoms among adolescents in the Wellington region by area and ethnicity. NZ Med F 1993;106:239-41.

2 Forero R, Bauman A, Young L, Larkin P. Asthma prevalence and management in Australian adolescents: results from three community surveys. $f$ Adolesc Health 1992:13:70712.

3 Kolnaar B, Beissel E, van-den-Bosch WJ, Folgering H, vanden-Hoogen HJ, van Weel C. Asthma in adolescents and young adults: screening outcome versus diagnosis in general practice. Fam Pract 1994;11:133-40

4 Rimpela AH, Savonius B, Rimpela MK, Haahtela T. Asthma and allergic rhinitis among Finnish adolescents in 19771991. Scand $\mathcal{F}$ Soc Med 1995;23:60-5.

5 Office of Population and Census Surveys. DH2 17-19. London: HMSO.

6 Rubinfeld AR, Pain MCF. Perception of asthma. Lancet 1976;i:882-4.

7 MORI. Young adults with asthma - a qualitative study. Report of a research study for the National Asthma Campaign, 1991.

8 Lenney W, Wells NEJ, O'Neill BA. Burden of childhood asthma. Eur Respir Dis 1994;4:49-62.

9 Bevis M, Taylor B. What do school teachers know about asthma? Arch Dis Child 1990;65:622-5.

10 Rupp NT, Guill MF, Brudno DS. Unrecognized exercise induced bronchospasm in adolescent athletes. $A m \mathcal{F} D$ is Child 1992;146:941-4.

11 Bransford RP, McNutt GM, Fink JN. Exercise induced asthma in adolescent gym class population. Int Arch Allergy Appl Immunol 1991;94:272-4.

12 Townsend J, Wilkes $\mathrm{H}$, Haines A, Jarvis $M$. Adolescent smokers seen in general practice: health, lifestyle, physical measurements and response to antismoking advice. $B M \mathcal{F}$ 1991;303:947-50.

13 Donovan CF, McCarthy S. Is there a place for adolescent screening in general practice? Health Trends 1988;2:20-64.

14 Ostrov MR, Ostrov E. The self image of asthmatic adolescents. F Asthma 1986;23:187-93.

15 Seigel WM, Golden NH, Gough JW, Lashley MS, Sacker IM. Depression, self esteem and life events in adolescents with chronic diseases. $¥$ Adolesc Health Care 1990;11: with chro 4 .

16 Silverglade L, Tosi DJ, Wise PS, D-Costa A. Irrational beliefs and emotionality in adolescents with and without bronchial asthma. F Gen Psychol 1994;121:199-207.

17 Catford JC, Nutbeam D, Woolaway M. Effectiveness and cost benefits of smoking education. Community Med 1984; 6:264-72.

18 Lader D, Matheson J. Smoking among secondary school children in 1990. London: HMSO, 1991.

19 Brook U, Shiloh S. Attitudes of asthmatic and nonasthmatic adolescents toward cigarettes and smoking. Clin Pediatr 1993;32:642-6.

20 Townsend JL, Smoking and lung cancer: a cohort data study of men and women in England and Wales, 19351970. $\mathcal{F} R$ Stat Soc 1978;141:95-107.

21 Hanrahan JP, Tager IB, Segal MR, Tosteson TD, Castile RG, Van Vunakis $\mathrm{H}$ et al. The effect of maternal smoking during pregnancy on early infant lung function. $\mathrm{Am} \mathrm{Rev}$ Respir Dis 1992;145:1129-35.

22 Ley P. Communicating with patients: improving communication, satisfaction and compliance. New York: Chapman and Hall, 1988:53-71.

23 Rand CS, Wise RA. Measuring adherence to asthma medication regimens. Am $\mathcal{f}$ Respir Crit Care Med 1994;149. ication

24 Evans D. To help patients control asthma the clinician must be a good listener and teacher. Thorax 1993;48:685-7.

25 Sibbald B. Patient self care in acute asthma. Thorax 1989; 44:97-101.

26 Kemp D, Meltzer EO. Beta ${ }_{2}$ adrenergic agonists: oral or aerosol for the treatment of asthma? $\mathcal{F}$ Asthma 1990;27: 149-57.

27 Pedersen S, Frost L, Arnfred T. Errors in inhalation technique and efficacy of inhaler use in asthmatic children. nique and efficacy of in

28 Mas JC, Resnick DJ, Firschein DE, Feldman BR, Davis WJ. Misuse of metered dose inhalers by house staff members. Am $\mathcal{F}$ Dis Child 1992:146:783-5.

29 Becker MH. Patient adherence to prescribed therapies. Med Care 1985;23:539-55.

30 Coutts JAP, Gibson NA, Paton JY. Measuring compliance with inhaled medication in asthma. Arch Dis Child 1992; 67:332-3.

31 Merkus PJFM, van Essen-Zandvliet EEM, Duiverman EJ, van Houwelingen HC, Kerrebijn KF, Quanjer PH. Long term effect of inhaled corticosteroids on growth rate in adolescents with asthma. Pediatrics 1993;91:1121-6.

32 Cary J, Hein K, Dell R. Theophylline disposition in adolescents with asthma. Ther Drug Monit 1991;13:309-13.

33 Sampson AP, Castling DP, Green CP, Price JF. Persistent elevation in plasma and urinary leukotrienes after acute asthma. Arch Dis Child 1995;73:221-5. 